\title{
WELCOMING REMARKS OF THE RECTOR OF INSTITUTE OF TECHNOLOGY, BANDUNG
}

Distinguished members of the International Astronomical Union from all over the world, Distinguished scientists and researchers in astronomy, astrophysics, geophysics, physics, and other sciences, present in this important meeting,

Distinguished guests,

Ladies and gentlemen,

It is indeed an honour and a pleasure for me to welcome you all to this International Astronomical Union Symposium Number 143 on Wolf-Rayet Stars and Interrelations with other Massive Stars in Galaxies, which is held in Denpasar, Bali, from June 18 to 22, 1990.

Welcome to Indonesia and welcome to the island of Bali. I am happy that this gathering is held in Indonesia.

I wish to express my thanks to the IAU and the Government of Indonesia and other sponsoring organizations for the opportunity, the trust, and assistance given to Indonesia, including the Institute of Technology Bandung (ITB) and the Udayana University, to host this international symposium.

It is indeed appropriate and fortunate that this scientific meeting is held at this particular time, because today an increasing emphasis is given to strengthening and developing mathematics and natural sciences in Indonesia. For science and technology to contribute meaningfully to the development of Indonesia, such an effort to developing the basic sciences is mandatory.

Ladies and gentlemen,

Astronomy, as a part of science that tries to unlock the mysteries of the origins of our stellar system and the galaxies, I know, can and will give answers to questions relating to the existence of our earth and life on earth. It is my sincere believe that ideas from deliberations in this meeting will lift the spirit and awaken inspirations to find answers to scientific questions about our stars and galaxies and to make conjectures and predictions of the future of our universe and the future of science and mankind. Above all, I hope cooperation and mutual understanding will be renewed among all the participants in this meeting so that new and existing scientific data can be shared and transformed into information for the benefit of man.

On behalf of the academic and research community of the Institute of Technology Bandung and joining the Indonesian community of scientists and the host committee, I wish you a succesful symposium that will contribute new information for the sciences represented here.

May I also wish you a pleasant stay in Bali.

Thank you.

Prof.Ir. Wiranto Arismunandar

9

K. A. van der Hucht and B. Hidayat (eds.),

Wolf-Rayet Stars and Interrelations with Other Massive Stars in Galaxies, 9.

(c) 1991 IAU. Printed in the Netherlands. 